\title{
The histological changes induced by Cytarabine on rabbits livers (with and without vitamin $\mathrm{E}$ administration)
}

\author{
S. Al-Jammas ${ }^{1}$ and A. Al-Saraj ${ }^{2}$ \\ Department of Basic Sciences, College of Dentistry, University of Mosul, Mosul, Iraq \\ Email: ${ }^{1}$ saifaljammas@uomosul.edu.iq, ${ }^{2}$ ayadrehman@uomosul.edu.iq
}

(Received November 10, 2018; Accepted December 23, 2018)

\begin{abstract}
The present study was intended to determine the histological changes induced by Cytarabine drug on the structure of rabbit's livers and the protective effects of vitamin $\mathrm{E}$ on these histological changes. The treated group with daily intraperitoneal dose of $(50 \mathrm{mg} / \mathrm{kg}$ body weight) of Cytarabine alone, showed a massive histological change represented by infiltration of mononuclear inflammatory cells, epithelioid cell and Kupffer's cells in hepatic tissue. Fibrosis in portal area, congestion of blood vessels as well as hyperplasia of bile canaliculi and coagulative necrosis of hepatocytes were also noticed in other sections. While the group that received protective ( $800 \mathrm{IU}$ of vitamin E) prior to each Cytarabine injection, showed a considerable histological improvement than the group received Cytarabine alone, as the histological sections of this group showed a nearly normal histological architecture of the liver that represented by normal arrangement of hepatic cords, no fibrosis no congested blood vessels were seen. though distension of hepatic sinusoids and coagulative necrosis of some hepatocytes were still observed. The present study suggested that vitamin E is an effective chemo-protective agent against hepatotoxicity when used as a protective agent prior to Cytarabine drug taken.
\end{abstract}

Keywords: Cytarabine, Rabbits livers, Vitamin E

Available online at http://www.vetmedmosul.com, (C) 2020, College of Veterinary Medicine, University of Mosul.

This is an open access article under the CC BY 4.0 license (http://creativecommons.org/licenses/by/4.0/).

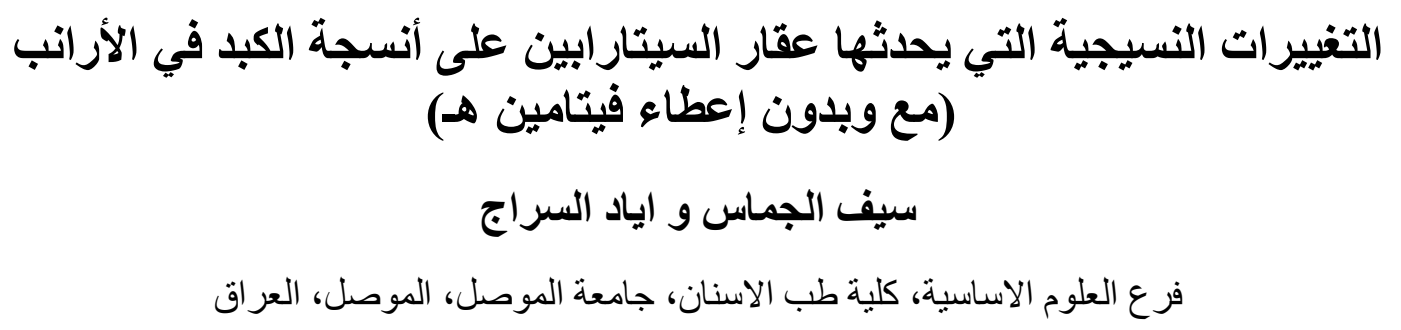

الخلاصة

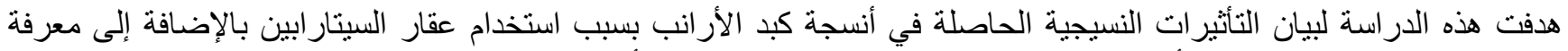

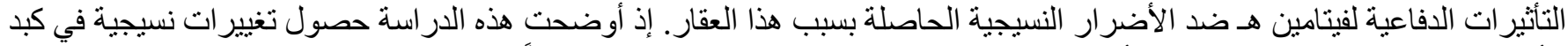

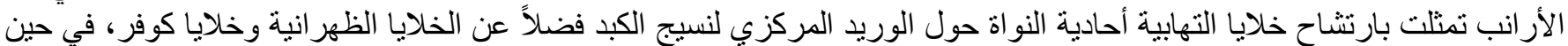

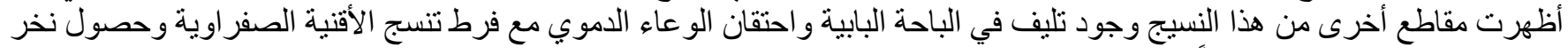

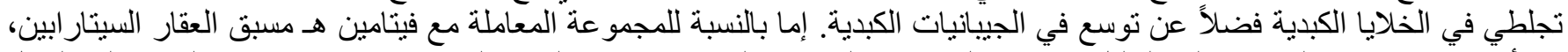

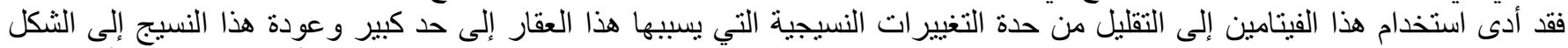

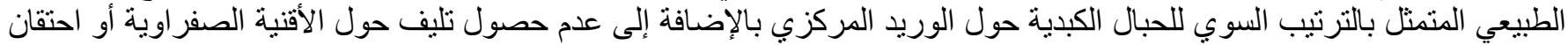

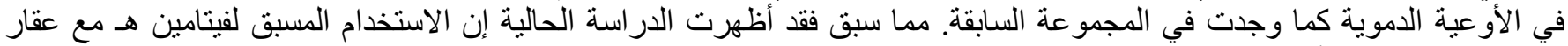

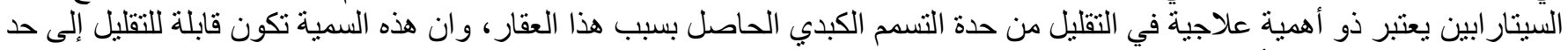

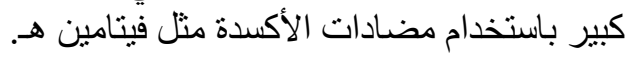




\section{Introduction}

Chemotherapy is a successful and routine treatment for many types of malignances (1). Cancer treatment was subjected to an important progress in last few years, when the oncology approaches had improved significantly for numerous patients. These patients whom suffered previously from chemotherapeutic drugs failures are now getting an important result with the reduced progression of cancer as well as increasing the rate of survival (2). Regardless of this significant progression in chemotherapy drugs for many malignant diseases, the hepatotoxicity stays one of the chief side effects and sometimes become a lifethreatening problem (3).

Cytarabine, known as Ara-C, is a chemotherapy drug (antimetabolite) used mainly in treatment of cancers of white blood cells just like Non-Hodgkin lymphoma and acute Myeloid Leukemia. It causes cancer cells death by inhibition of DNA polymerase via competition with deoxycytidine triphosphate, leading to inhibition of DNA synthesis (4). Cytarabine is called cytosine arabinose because it joins an arabinose sugar with cytosine base (4). Cytosine is normally combining with a (deoxyribose sugar) to form deoxycytidine, which is a DNA component. Cytosine arabinoside is nearly similar to the cytosine deoxyribose (deoxycytidine) of the human to be incorporated inside human DNA but sufficiently different to terminate malignant cells, finally cancer cells would be killed by this mechanism (5). Acute liver injury (hepatotoxicity) is one of the most popular forms of hepatic diseases that could occur as consequences of cytotoxic treatment (6). The objective of this study is to explain the histological changes induced by Cytarabine on the structure of rabbits livers and the protective effects of vitamin $\mathrm{E}$ on these histological changes.

\section{Materials and methods}

\section{Laboratory animals}

The study is carried out on rabbits weighing $1.5-2.0 \mathrm{~kg}$, obtained from Pharmaceutical Control Department (Ministry of Health \& Environment), aged three months. The rabbits were permitted to adapt to laboratory circumstance 6 days before starting the experiment and caged in a temperature controlled chamber $\left(23 \pm 4^{\circ} \mathrm{C}\right)$ with a 12 hours of light/dark cycle. They were permitted to drink tap water freely and daily fed by food pellet consisting of $22 \%$ protein and under good laboratory circumstances.

\section{Experimental design}

The rabbits were separated into 3 experimental groups $(\mathrm{n}=6)$, Group A: was given $1 \mathrm{ml}$ of intraperitoneal injection of normal saline once a day for 1 week and served as a control group. Group B: was given a daily intraperitoneal dose of $50 \mathrm{mg} / \mathrm{kg}$ body weight Cytarabine only for 1 week. Group C: was given a daily oral dose of $800 \mathrm{IU}$ of vitamin E 5 hours before it receives the daily intraperitoneal dose of (50 mg/kg body weight) Cytarabine for 1 week. The Intraperitoneal injections were given in the lower lateral part of the abdomen. The rabbits of all 3 groups were scarified after seven days under light ether anesthesia.

\section{Tissue preparation for histological study}

The liver of each rabbit was prepared for histological study as the samples of each liver were placed in solution of $10 \%$ formalin for a period of 24 hours for fixation, after that the tissues were dehydrated using a gradual concatenations of alcohol solution $(50 \%-100 \%)$ for 5 minute each. Then the tissue samples were cleared in 2 separated xylene changes prior to placing them in paraffin wax for final sectioning. Later the samples were sectioned at $5 \mu \mathrm{m}$ thickness, then it stained by hematoxylin and eosin stain to study the histological changes compared to the control group using light microscope (7).

\section{Results}

Histological structure of the liver sections of group A (control group) appeared to be normal as we can see a normal histological architecture of the liver with normal central vein $(\mathrm{CV})$ from which chords of hepatocytes are radiating (Figure 1). The liver sections of group B (Cytarabine treated group) showed infiltration of inflammatory cells around central venule of hepatic tissue and fibrosis (Figure 2). Other sections showed infiltration of mononuclear inflammatory cells in addition to epithelioid cell and Kupffer's cells in hepatic tissue (Figure 3). Fibrosis in portal area, congestion of blood vessels, hyperplasia of bile canaliculi and inflammatory cells infiltration in portal area were also observed (Figure 4, 5). Finally, coagulative necrosis of hepatocytes and distension of hepatic sinusoids could also be noticed in other sections (Figure 6). The liver sections of group C (Cytarabine treated group with vitamin $\mathrm{E}$ protection) showed a nearly normal histological architecture of liver tissue that represented by a normal arrangement of hepatic cords, neither fibrosis nor congested blood vessels were seen with distension of hepatic sinusoids and coagulative necrosis of few hepatocytes were still observed (Figure 7). infiltration of macrophages and hyperplasia of Kupffer's cells were noticed in other sections (Figure 8). 


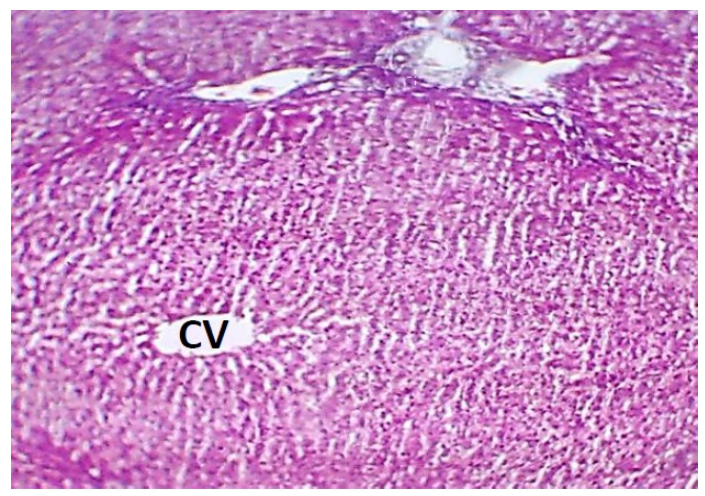

Figure 1: Histological section of liver tissue of group A (control group) showing normal histological architecture, with central vein $(\mathrm{CV})$ from which chords of hepatocytes are radiating. $\mathrm{H} \& \mathrm{E}, 100 \mathrm{x}$.

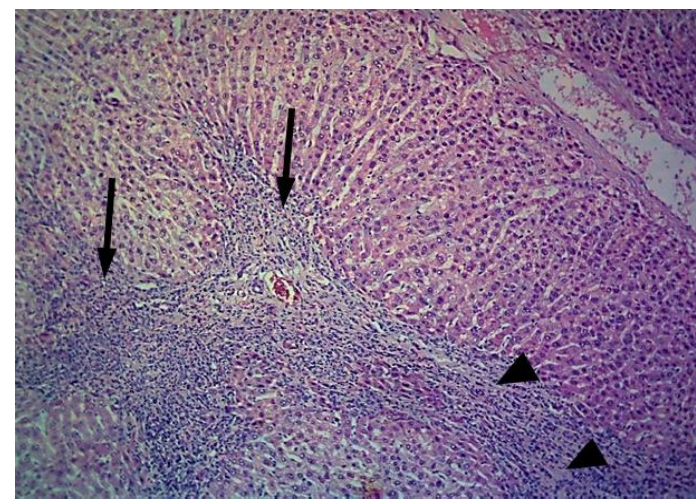

Figure 2: Histological section of rabbit's liver from group $\mathrm{B}$, showed infiltration of inflammatory cell around central venule of hepatic tissue (arrow), with fibrosis (arrow head). H\&E, 100x.

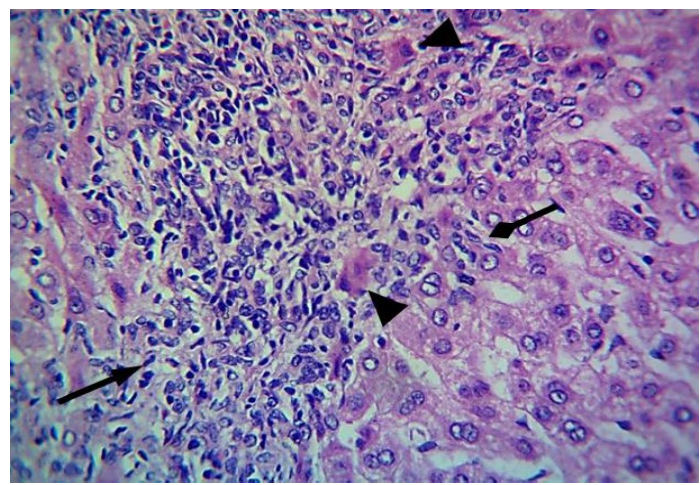

Figure 3: Histological section of rabbit's liver from group $\mathrm{B}$, showed infiltration of mononuclear inflammatory cells in hepatic tissue (black arrow), in addition to epithelioid cell (arrow head), and Kupffer's cells (triangular arrow). $\mathrm{H} \& \mathrm{E}, 400 \mathrm{x}$.

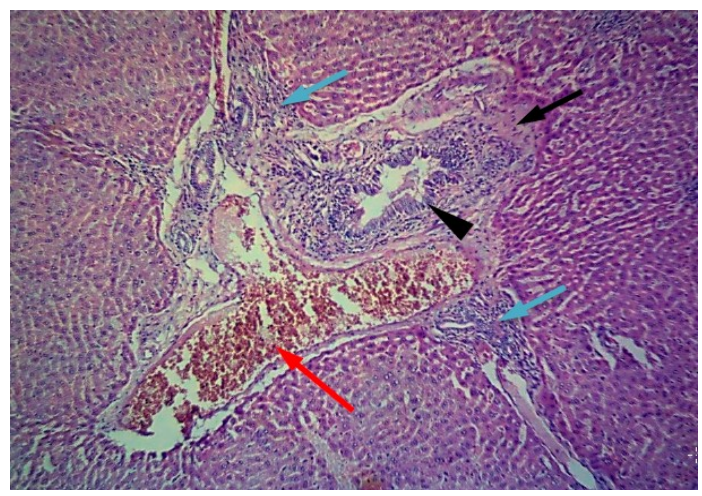

Figure 4: Histological section of rabbit's liver from group $\mathrm{B}$, showed fibrosis in portal area (black arrow), congestion of blood vessels (red arrow), hyperplasia of bile canaliculi (arrow head), with infiltration of inflammatory cells in portal area (blue arrow). H\&E, 100x.

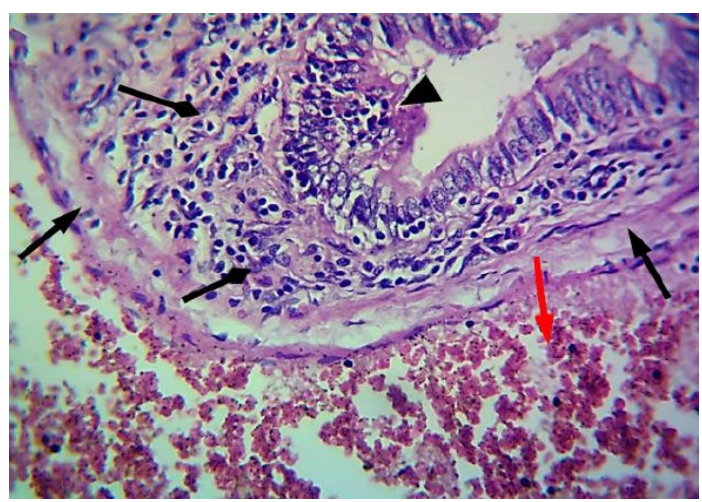

Figure 5: Histological section of rabbit's liver from group $\mathrm{B}$, showed fibrosis in portal area (black arrow), congestion of blood vessels (red arrow), hyperplasia in bile canaliculi (arrow head), infiltration of mononuclear inflammatory cells in portal area (triangular arrow). H\&E, 400x.

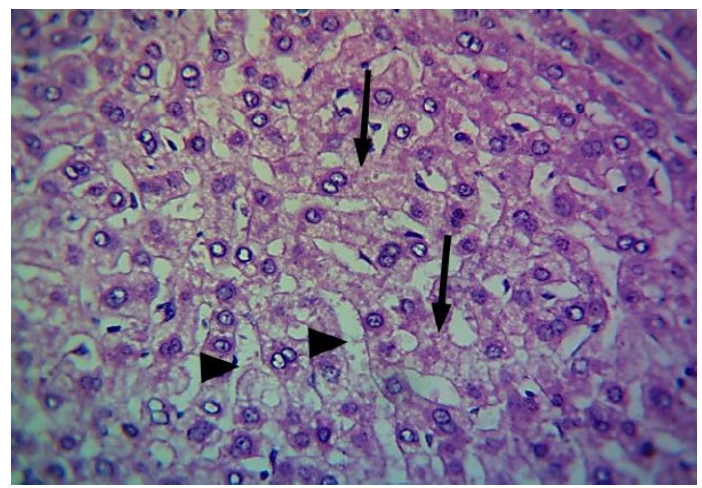

Figure 6: Histological section of rabbit's liver from group B, showed coagulative necrosis of hepatocytes (arrow), distension of hepatic sinusoids (arrow head). H\&E, 400x. 


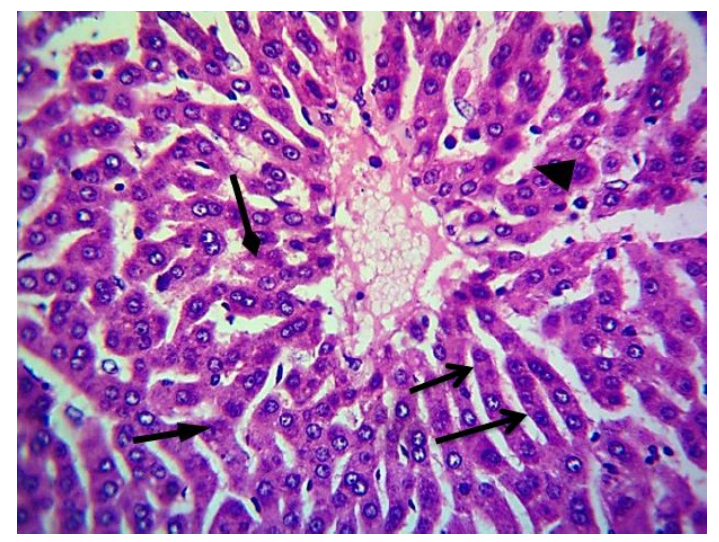

Figure 7: Histological section of rabbit's liver from group $\mathrm{C}$, showed normal arrangement of hepatic cords (black arrows), distension of hepatic sinusoids (arrow head), with few hepatic cells showed coagulative necrosis (triangular arrow). H\&E, 400x.

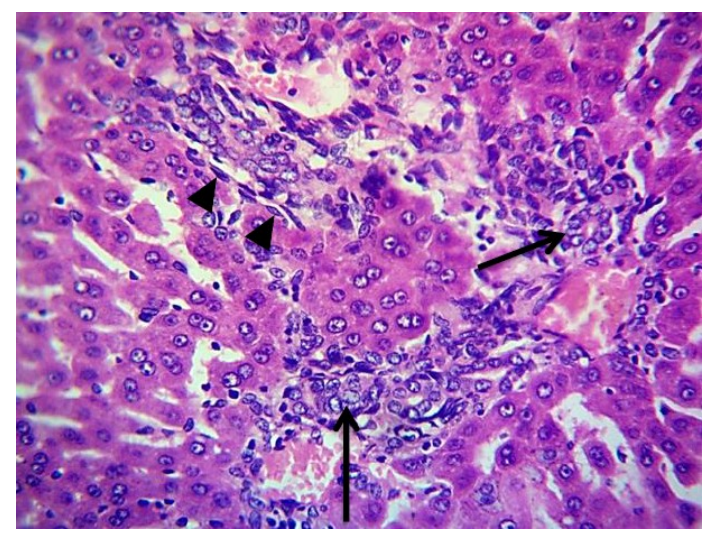

Figure 8: Histological section of rabbit's liver from group $\mathrm{C}$, showed infiltration of macrophages (arrow), with hyperplasia of Kupffer's cells (arrow head). H\&E, 400x.

\section{Discussion}

Most of the cytotoxic drugs that are used to treat malignant diseases can cause different hepatic problems, because this organ (liver) plays an important role in the metabolism of these medications in addition to that; the liver has a rich blood supply which makes the hepatic injury is a common problem related to chemotherapeutic drugs administration (8).

This work regarded as first experimental study focuses on the histological changes in liver tissues induced by Cytarabine and the protective rule of vitamin E against Cytarabine induced hepatic injury, as most of the previous researches carried out on human patients, found a strong relation between high doses of Cytarabine and hepatotoxicity (9), but these studies were focusing on clinical manifestations and parameters like "liver function tests" not histological changes, as well as no antioxidant like vitamin E was used in those experiments as a protective agent.

The hepatotoxicity observed in group B is represented by many histological changes, like infiltration of mononuclear inflammatory cells, epithelioid cell and Kupffer's cells in hepatic tissue. Fibrosis in portal area, congestion of blood vessels, hyperplasia of bile canaliculi as well as coagulative necrosis of hepatocytes and distension of hepatic sinusoids were also seen. These histological changes were in agreement with the experimental studies conducted by other researchers and it could mostly be attributed to inflammatory reactions $(10,11)$.

The hepatic cells are well known to accumulate significant amounts of Cytarabine, so hepatotoxicity could be caused by Cytarabine storage in hepatocytes (10). This tissue can be damaged by Cytarabine via different mechanisms like reactive oxygen species formation and generation of oxidative stress, as most of the cytotoxic drugs cause induction of reactive oxygen species $(12,13)$. These reactive oxygen species (ROS) cause an inflammatory reaction within hepatic tissue that finally leads to infiltration of mononuclear inflammatory cells (14). Kupffer's cells reappear as a crucial mediator of hepatic damage and repair, these cells display a massive flexibility depending on the immune and metabolic status, then they show different types of polarized phenotypes each participate in the management of wound healing and inflammation (15).

Chronic liver injury is well recognized by hepatic fibrosis. In normal conditions, stellate cells of the livers Tay dormant but they become activated in reaction to injuries, these activated stellate cells are recognized as fibrogenic agents that finally cause collagen fibers deposition (16).

Endothelial cells injury lining hepatic sinusoids that occur in reaction to reactive oxygen species and oxidative stress generation consequent to Cytarabine administration leads to loss of sinusoidal wall integrity followed by blockage of hepatic sinusoid by embolized endothelial cells lining these sinusoids. Sinusoidal endothelial cells embolization would block venous outflow and impair sinusoidal microcirculation resulting in hepatocytes necrosis, sinusoidal dilatation and hepatic blood vessels congestion $(9,17)$.

Concerning group $\mathrm{C}$ which was treated with vitamin $\mathrm{E}$ as antioxidant before each Cytarabine administration, the histological changes noted in this group showed a significant improvement of the liver tissues in comparison with that of Group B, as it showed nearly normal histological architecture of liver that represented by normal arrangement of hepatic cords, no fibrosis in portal area, no congestion of blood vessels with presence of few necrotic 
hepatic cells relatively. These findings are previously described and supported by other researchers whom stated that use of antioxidant agents, would be capable of normalizing the histological changes induced by Cytarabine and reduce Cytarabine provoked hepatotoxicity when compared with antioxidant non-treated group $(18,19,20)$.

The mechanism by which vitamin $\mathrm{E}$ reduces the Cytarabine caused hepatotoxicity is returned to the fact that, vitamin $\mathrm{E}$ reduces the oxidative damage of Cytarabine by activating antioxidant defense mechanism and reducing lipid peroxidation (21) or by awarding electrons to the active free radicals to extinguish their effectiveness thus reducing the oxidative stress either by its antioxidant scavenging activity or by returning the efficacy of antioxidant enzymes to their ordinary levels $(22,23)$.

In conclusion, the present study reveals that vitamin $\mathrm{E}$ showed antioxidant, free radical scavenging and hepatoprotective activity versus Cytarabine caused hepatotoxicity without affecting the tumor control efficacy of Cytarabine (24). However, Further studies are needed to assess the level of protection provided by vitamin $\mathrm{E}$ at various dosages and at various times before each Cytarabine administration.

\section{Acknowledgment}

The Authors are very grateful to the University of Mosul/ College of Dentistry for their provided facilities, which helped to improve the quality of this work.

\section{References}

1. Desai AG, Qazi GN, Ganju RK, El-Tamer M, Singh J, Saxena AK, Bedi YS, Taneja SC, Bhat HK. Medicinal plants and cancer chemoprevention. Curr Drug Metab. 2008;9(7):581-591. PMC4160808.

2. Sahni V, Choudhury D, Ahmed Z. Chemotherapy-associated renal dysfunction. Nat Rev Nephrol. 2009;5(8):450-462. DOI: 10.1038/nrneph.2009.97.

3. Grigorian A, O'Brien CB. Hepatotoxicity secondary to chemotherapy. J Clin Transl Hepatol. 2014;2(2): 95-102. DOI: $10.14218 / \mathrm{JCTH} .2014 .00011$.

4. Finkel KW, Foringer JR. Renal disease in patients with cancer. Nat Clin Pract Nephrol. 2007;3(12):669-678. DOI: 10.1038/ncpneph0622

5. Al-Jammas S, Al-Sarraj A. The histological changes induced by cytarabine on rabbits kidneys (with and without vitamin $\mathrm{E}$ administration). Iraqi Journal of Veterinary Sciences. 2019; 33(2): 311-316. DOI: 10.33899/ijvs.2019.162910.

6. Konda N, Prashanth P, Arvind G, Shah S. Pharmaceutical development and compatibility studies on cytarabine injection. Asian J Pharm Clin Res. 2013;3(6):42-145. DOI: 0974-2441
7. Luna LG. Manual of Histologic Staining Methods of the Armed Forces Institute of Pathology. 3rd ed., McGraw-Hill Book Co., USA. 1968; pp. 3-158.

8. Norbert L. Nephrotoxicity of recent anti-cancer agents. Clin Kidney J. 2014;7(1):11-22. DOI: $10.1093 / \mathrm{ckj} / \mathrm{sft} 135$

9. Maor Y, Malnick S. Liver injury induced by anticancer chemotherapy and radiation therapy. Int J Hepatol. 2013;2013:815105. DOI:10.1155/2013/815105

10. King PD, Perry MC. Hepatotoxicity of chemotherapy. Oncol. 2001;6:162-176. DOI: 10.1634/theoncologist.6-2-162

11. El-Sayyad HI, Ismail MF, Shalaby FM, Abou-El-Magd RF, Gaur RL, Fernando A. Histopathological effects of cisplatin, doxorubicin and 5flurouracil (5-FU) on the liver of male albino rats. Int J Biol Sci. 2009;5(5):466-73. DOI:10.7150/ijbs.5.466.

12. Al-Majed AA. Carnitine deficiency provokes cisplatin-induced hepatotoxicity in rats. Basic Clin Pharmacol Toxicol. 2007;100(3):145-150.DOI:10.1111/j.17427843.2006.00024.x

13. Fang J, Nakamura H, Iyer AK. Tumor-targeted induction of oxystress for cancer therapy. J Drug Target. 2007;15:475-486. DOI:10.1080/10611860701498286.

14. Cruz CM, Rinna A, Forman HJ, Ventura AL, Persechini PM, Ojcius DM. ATP activates a reactive oxygen species-dependent oxidative stress response and secretion of proinflammatory cytokines in macrophages. J Biol Chem. (2007);282:2871-2879. DOI:10.1074/jbc.M608083200.

15. Ju C, Tacke F. Hepatic macrophages in homeostasis and liver diseases: From pathogenesis to novel therapeutic strategies. Cell Mol Immunol. 2016;13:316-327. DOI: 10.1038/cmi.2015.104

16. Dixon LJ, Barnes M, Tang H, Pritchard MT, Nagy LE. Kupffer cells in the liver. Compr Physiol. 2013;3(2):785-97. DOI:10.1002/cphy.c120026

17. Canbay A, Taimr P, Torok N, et al. Apoptotic body engulfment by a human stellate cell line is profibrogenic. Lab Invest. 2003;83:655-663. PMID: 12746475

18. Stevenson HL, Prats MM, Sasatomi E. Chemotherapy-induced Sinusoidal Injury (CSI) score: a novel histologic assessment of chemotherapy-related hepatic sinusoidal injury in patients with colorectal liver metastasis. BMC Cancer. 2017;17(1):35. DOI:10.1186/s12885-016-2998-2.

19. Tarladaçalışır YT, Uygun M, Akpolat M, UzHülya Y. Histologic examination of the protective effect of vitamin $\mathrm{E}$ and $\mathrm{C}$ in cisplatininduced hepatotoxicity. Balkan Med J. 2005;22:124-131. PMC3897034.

20. Ahmad RM, Al-Jawary AA. Effect of vitamin C on the hepatotoxicity induced by cisplatin in rats. Raf J Sci. 2012;23(2):23-33. DOI: 10.22127/rjp.2019.84314

21. Shona S, Essawy AW, Zaki SM, EI-Galil TI. Effect of cisplatinum on the liver of the adult albino rat and the possible protective role of vitamin E (histological and ultrastructural study). Anat Physiol. 2012;2:102. DOI: 10.4172/2161-0940.1000102.

22. El-Gendy KS, Aly NM, Mahmoud FH, Kenawy A, El-Sebae AK. The role of vitamin $\mathrm{C}$ as antioxidant in protection of oxidative stress induced by imidacloprid. Food Chem Toxicol. 2010;48(1):215-221. DOI: $10.1016 /$ j.fct.2009.10.003

23. Maheswari E, Saraswathy GR, Santhranii T. Influence of vitamin E on hepatotoxicity and oxidative stress. 2015;2(3):30-38. DOI: 2394-5893

24. Singh KC, Kaur R, Marar T. Ameliorative effect of vitamin E on chemotherapy induced side effects in rat liver. J Pharmacol Toxicol. 2011;6:481-492.DOI: 10.3923/jpt.2011.481.492. 